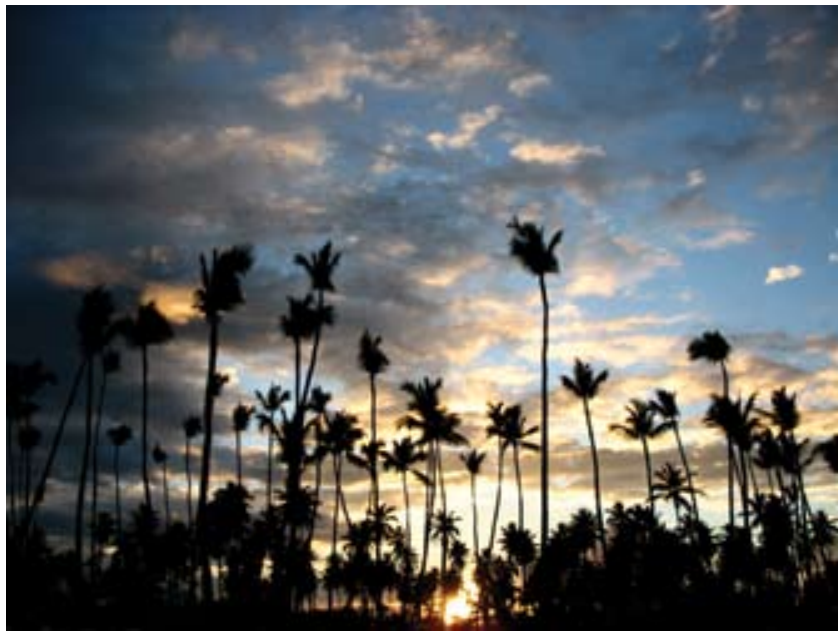

\title{
WHAT'S UNDOCUMENTED
}

There's a calm stillness

To the sick at night-

The sound of quiet healing, I hope,

But inevitably, a few cannot be healed.

Some patients walk that journey slowly, with

Humble shoulders slouched, weathered eyes closed,

Faltering against heavy feet.

Others stand and then seem to fall,

Out of nowhere, out of nothing,

Suddenly without breath, or pulse, or chance.

It can seem futile, our work,

At those moments, or sometimes tragic.

We don't know the person being saved as a person well-

Their stories, their triumphs, their beginning-

We see only their scars, their end.

We then write a story in medical prose

That has its own inevitable circle-

A downward tailspin of vital signs, recorded in jargon,

Meant to document the loss of a life.

Death and dying as a sterile procedure,

That we all know is contaminated

By private prayers and irrational hope,

Questions about mortality and afterlife,

Suppressed emotions and subjectivity.

We leave out details, of course, of the heaviness,

Or sometimes the supreme lightness

That is somehow left-

Pervasive, tense, uncertain-

Undocumented and unspoken, but captured within.

Tamara Solitro, $M D$

\section{Dominican}

Photo courtesy of

Ana Shnitser, MD 